\title{
Evaluating needs for care of psychiatric patients
}

\author{
GRAHAM THORNICROFT
}

\section{INTRODUCTION}

This paper addresses the following question: how may needs for mental health care and services, both for patients and their carers, be defined and measured?

\section{DEFINING NEED}

Needs may be defined in terms of impairment, disability, or in terms of interventions. The fact that a need is defined does not mean that it can be met. For example, some needs may remain unmet because other problems take priority, because an effective method is not available locally, or because the person in need refuses treatment.

A need may exist, as defined by a professional, even if the intervention is refused by a patient. Further, a needs assessment is not intended to endorse the status quo. It is important to define need in terms of the care/agent/setting required, not those already in place. At the same time, a proper needs assessment process should not lead to the imposition of expert solution upon patients. A professionally defined need remain unmet, and have to be replaced by one acceptable to the patients.

The specification of an intervention, if accepted by the user following negotiation, leads to the choice of a key worker to provide the care (Mangen \& Brewin, 1991). In addition, it is important to distinguish need from demand, provision and utilisation (Figure 1 from Stevens \& Gabbay, 1991).

Indirizzo per la corrispondenza: Dr. G. Thornicroft, Prism, Institute of Psychiatry, De Crespigny Park, Denmark Hill, London SES 8AF (England).

Fax $(+44)$ 71-277.1462.

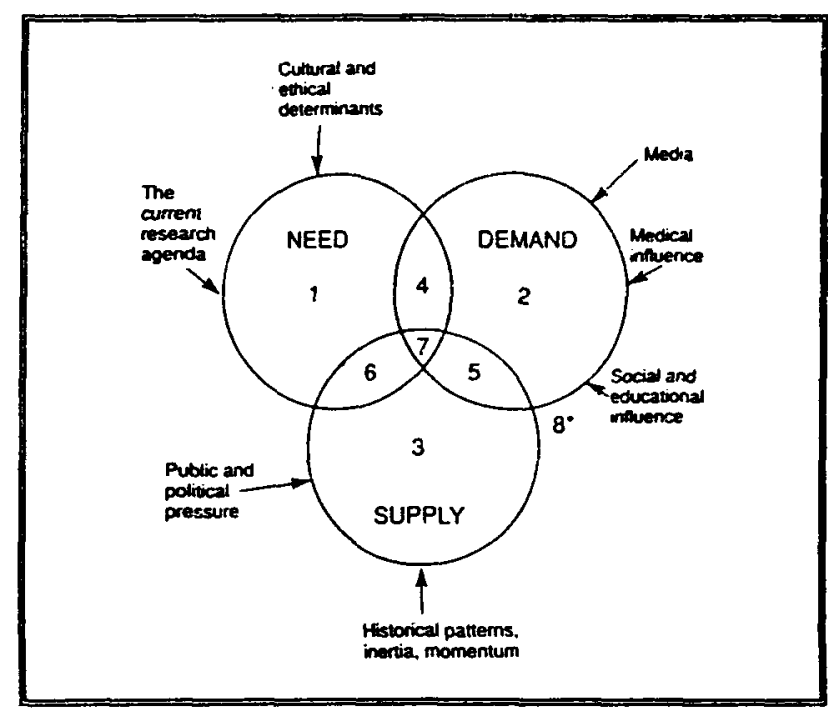

Figure 1. - Need, demand and supply: influences and overlaps.

* The external field where a potential service is not needed, demanded or supplied.

NEED = What people benefit from.

DEMAND = What people ask for.

SUPPLY $=$ What is provided.

\section{DEMAND}

A demand for care exists when an individual expresses a wish to receive it. Some demands are expressed in an unsophisticated form; e.g. «something needs to be done». The user should be involved in a negotiation as to what interventions should be provided for what problems. This will include an explanation of the options. The process should not be purely directed by experts or professionals. 


\section{PROVISION}

Provision includes interventions, agents, and settings, whether or not used. Care co-ordination entails providing such a pattern of service after initial assessment and then updating the assessment regularly to assess outcomes and to modify the care if needs remain unmet. Over-provision is provision without need. Under-provision is need without provision (unmet need).

\section{UTILISATION}

Utilisation occurs when an individual actually receives care, for example, an inpatient admission. Need may not be expressed as demand; demand is not necessarily followed by provision or, if it is, by utilisation; and there can be demand, provision and utilisation without real underlying need for the particular service used.

\section{MEASURING INDIVIDUAL NEEDS FOR CARE}

In an ideal planning framework, a comprehensive needs assessment would be undertaken on all patients and the aggregated data would be used to plan the services. In practice this is seldom possible, but systematic assessment, review, and evaluation over months and years of contact should allow teams to work with their users to evolve services more appropriate to their needs (Brewin et al., 1987). Patients who suffer from severe mental illness have a range of needs which goes far beyond the purely medical, such as those described in the National Institute of Mental Health's document (1987) Toward a Model Plan for a Comprehensive Community-Based Mental Health System. In this paper Stevens \& Gabbay's (1991) working definition of need will be used, that is «the ability to benefit in some way from health (and social) care».

The issue of how best to make an assessment has taxed both researchers and clinicians, not least because their requirements differ. An ideal assessment tool for use in a routine clinic setting would be one which is brief, easily learned, takes little time to ad- minister, does not require the use of personnel additional to the usual clinical team, is valid and reliable in different settings and across gender and cultures, and above all, which can be used as an integral part of routine clinical work, rather than as a timeconsuming extra. Macdonald (1991) suggests that in addition they should be sensitive to change, their potential inter-rater and test-rater reliability should be high, and they should logically inform clinical management (Hillier et al., 1991; Thornicroft \& Bebbington, 1993). The decision of which to use will depend on whether the approach is to focus on particular diagnostic or care groups, and on the balance to be struck between economy of time and inclusiveness of the ratings, and should include a range of areas of clinical and social functioning, such as those included in the CAN (Camberwell Assessment of Need, Figure 2).

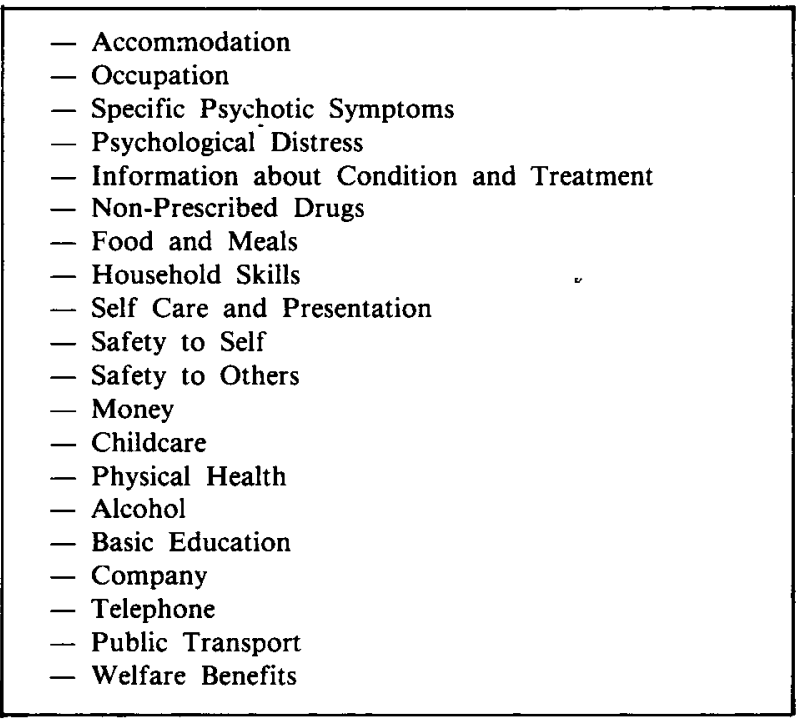

Figure 2. - Areas of potential need included in the CAN (Camberwell Assessment of Need).

\section{MEASURING POPULATION NEEDS FOR SERVICES}

Measuring the population's ability to benefit from health care generates two very specific information requirements (Wing, 1992). First, top-down sources of information such as the local prevalence and incidence of disease, ranged by severity. Prevalence, the number of cases per unit population at a point in time, or over a period, is usually the appropriate measure for chronic disease; and incidence, the number 
of new cases per unit time is usually appropriate for measuring acute disease. Second, the required type of information concerns the efficacy of the care and care settings available or potentially available to cope with it.

In practice several more detailed types of information are needed to assist judgements on how far mental health services meet need at the population level, especially resource costs and the number and characteristics of patients treated. Another potential approach is the measurement of Diagnostic Related Groups (Mitchell et al., 1987) which suggests that diagnosis is of little help in attempting to measure prospectively the resources required by individual inpatients. The relationship between individual-based needs assessment (bottom-up), and population-based information (top-down) is illustrated in Figure 3.

Traditionally service-level needs have been appro- ximated from service utilisation data, especially hospital bed use. This is now increasingly inaccurate because:

- in-patient care is a small and diminishing part of mental health care;

- in many respects in-patient care actually represents an alternative model of care to that practised (i.e. community based) for certain patients;

- the chronicity and episodic nature of mental illness means that episodes are often part of a longer sequence and are very varied in length and intensity; and

- there is a greater diversity of health professional contacts i.e. psychiatrists, psychologists, community psychiatric nurses, and occupational therapists.

In terms of the needs for general adult mental health services for a defined population, Figure 4 suggests that:

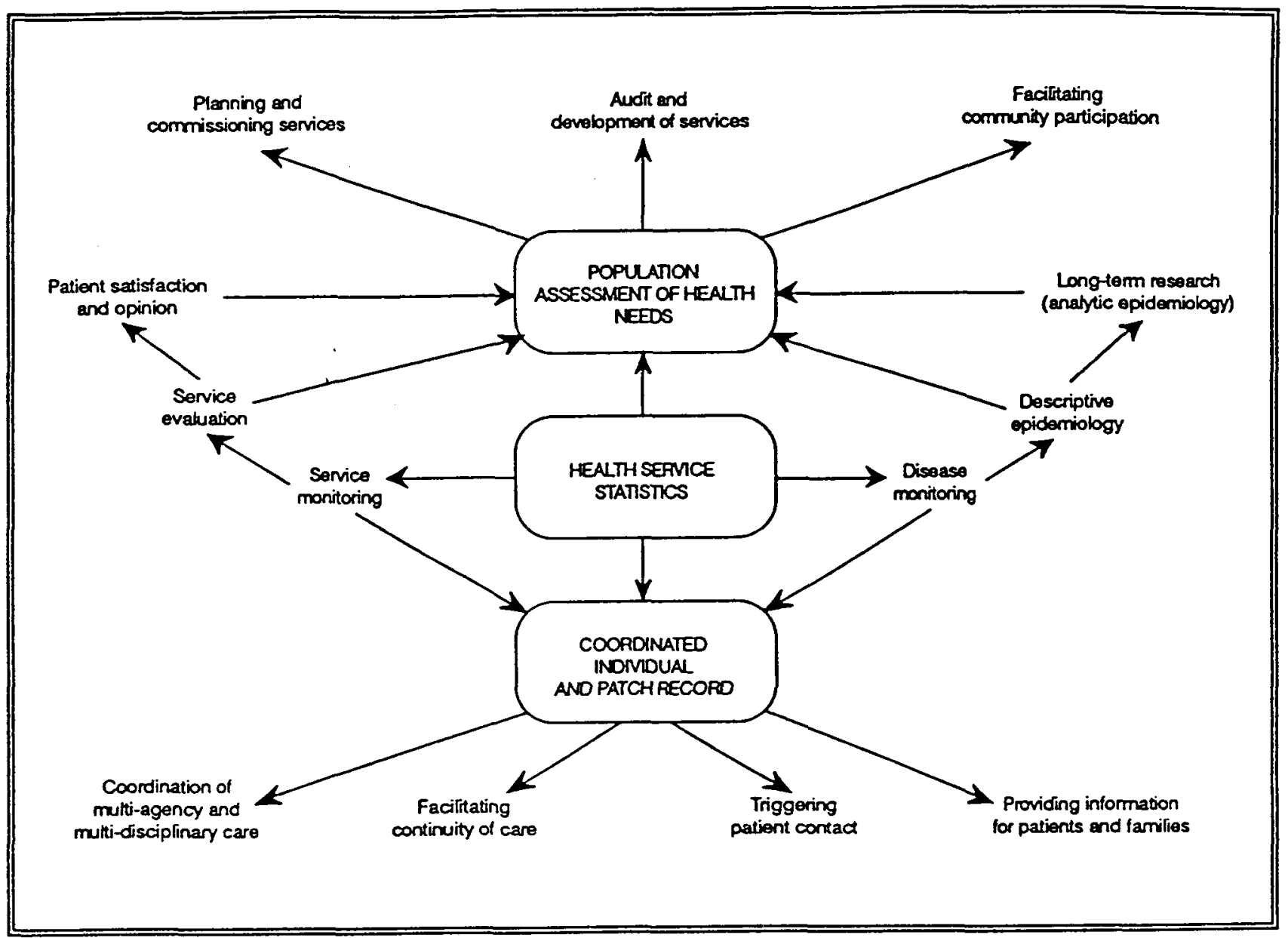

Figure 3. - Uses of Mental Health Information Systems. 
i) the emphasis should be upon the number of places available rather than upon the number of beds;

ii) a range of provisions should exist;

iii) the number of places needed in each category depends upon the extent of provision in the other categories, and that;

iv) the overall requirement for services will correlate closely with the degree of socio-economic deprivation experienced by that particular population, and therefore a range of places is given for each category.

\begin{tabular}{|l|ll|}
\hline Type of provision & \multicolumn{2}{|l|}{ Range of places } \\
\hline 24-hour staffed residences & 40 & 150 \\
Day-staffed residences & 30 & 120 \\
Acute psychiatric care & 50 & 150 \\
Unstaffed group homes & 48 & 80 \\
Adult-placement schemes & 0 & 15 \\
Local secure places & 5 & 10 \\
Respite facilities & 0 & 5 \\
Regional secure unit & 1 & 10 \\
\hline
\end{tabular}

Figure 4. - Proposed range of district acute and continuing care general adult psychiatric places for a 250,000 population.

\section{THE SERVICE NEEDS OF CARERS}

There is now a growing awareness that the families of mentally ill people may suffer very considerable burden and stress and that their needs may also require assessment. Kuipers (1992), for example, has emphasised the importance of

- the need for collaborative rather than adversarial relationships between professionals and carers;

- a need to understand;

- help in problem solving;

- need for emotional support;

- needs for care to continue;

- need to look after themselves;

- need for respite care;

- the needs of «peripheral» relatives.

\section{PRINCIPLES TO GUIDE SERVICES TO MEET UNMET NEEDS}

A broad consensus has emerged that needs-led, community-orientated psychiatric services should seek to embody the following principles:

a) Services should meet the range of special needs of psychiatric patients with particular attention being paid to those with physical disabilities, mental retardation, the homeless or imprisoned.

b) Services should be local and accessible and to the greatest extent possible delivered in the individual's usual environment.

c) Services should be comprehensive and address a wide range of needs.

d) Services should be flexible by being available whenever and for whatever duration needed.

e) Services should be consumer-orientated, that is, based on the needs of the user rather than those of providers.

f) Services should empower clients by using and adapting treatment techniques which enable clients to enhance their self-help skills and retain the fullest possible control over their own lives.

g) Services should be racially and culturally appropriate.

h) Services should focus on strengths, and should be built on the skills and strengths of clients to help them maintain a sense of identity, dignity and selfesteem.

i) Services should incorporate natural supports by being in the least restrictive, most natural setting possible. The usual work, education, leisure and support facilities in the community should be used in preference to specialised developments.

j) Services should be accountable to the consumers and informal carers and evaluated to ensure their continuing appropriateness, acceptability, and effectiveness on agreed parameters.

\section{CONCLUSION}

The assessments of needs for care and needs for services are in their infancy. But this is an «enfant terrible». Who should define needs? As yet, the issue of how service users participate in defining need is largely unexplored territory. Just as formidable is the question - what are the consequences of conducting proper needs assessment? In doing this, we are likely to confront previously inconspicuous portions of the pyramids of psychiatric morbidity and disability, with the inevitable subsequent question: how shall we prioritise services? 


\section{REFERENCES}

Brewin C. R., Wing J. K., Mangen S. P., Brugha T. S. \& MacCarthy B. (1987). Principles and practice of measuring needs in the long-term mentally ill: the MRC Needs for Care Assessment. Psychological Medicine 17, 971-982.

Hillier W., Zaudig M. \& Mobour W. (1991). Development of diagnostic checklists for use in routine clinical care. Archives of General Psychiatry 47, 782-784.

Kuipers L. (1992). Needs of relatives of long-term psychiatric patients. In Measuring Mental Health Needs (ed. G. Thornicroft, C. R. Brewin and J. Wing). Gaskell and Royal College of Psychiatrists: London.

Macdonald A. (1991). How can we measure mental health? In Indicators for Mental Health in the Population (ed. R. Jenkins and S. Griffiths). HMSO: London.

Mangen S. \& Brewin C. R. (1991). The measurement of need. In Social Psychiatry. Theory, Methodology and Practice (ed. P. E. Bebbington), pp. 162-182. Transaction Publishers: London.
Mitchell J., Dickey B., \& Liptzin B. (1987). Bringing psychiatric patients into the medicare prospective payments system: alternatives to DRGs. American Journal of Psychiatry 144, 610-615.

National Institute of Mental Health (1987). Toward a Model Plan for a Comprehensive Community-Based Mental Health System. MIMH: Washington.

Stevens A. \& Gabbay J. (1991). Needs assessment, needs assessment. Health Trends 23, 20-23.

Thornicroft G. \& Bebbington P. (1993). Quantitative methods in the evaluation of community mental health services. In $\mathrm{Mo}$ dern Community Psychiatry (ed. W. Breakey) (in press).

Thornicroft G., Brewin C. R., \& Wing J. (1992). Measuring Mental Health Needs. Gaskell and Royal College of Psychiatrists: London.

Wing J. K. (1992). Epidemiologically-Based-Needs-Assessments. Review of Research on Psychiatric Disorders. Department of Health: London. 
Cesario Bellantuono, Michele Tansella

\section{Gli psicofarmaci nella pratica terapeutica}

Terza edizione. Autunno 1993

Un libro di 720 pagine. Lire 88.000

Presentazione di Silvio Garattini, Direttore dell'Istituto di Ricerche

Farmacologiche Mario Negri di Milano.

Frutto di una revisione puntuale della precedente edizione, il libro si offre oggi allo specialista in Psichiatria ancora più organico e completo. L'opera fornisce informazioni costantemente orientate alla clinica ed $i$ contenuti sono stati aggiornati in modo diffuso e radicale, al punto che il volume si presenta con un numero di pagine quasi raddoppiato. Ben quattro sono i capitoli completamente nuovi rispetto alla seconda edizione: lo sviluppo dei nuovi psicofarmaci; il placebo; gli psicofarmaci in gravidanza; una bibliografia commentata della letteratura sull'argomento apparsa a livello internazionale negli ultimi trentacinque anni.

Ai Lettori di questa Rivista è offerta la possibilità di acquistare l'opera in anteprima ad un prezzo di particolare favore: lire 80.000 invece di lire 88.000, comprensive di spese di spedizione. L'ordine potra essere effettuato utilizzando la cedola sottostante, inviandola per posta o via fax:

\&

Desidero acquistare una copia di Gli psicofarmaci nella pratica terapeutica,

Terza edizione, al prezzo di lire 80.000 , invece di lire 88.000 .

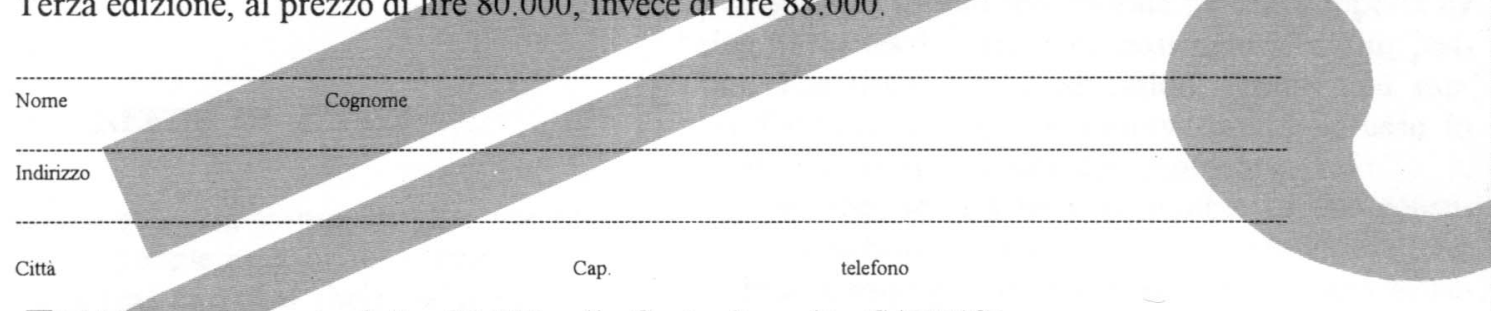

$\square$ Addebitate l'importo di lire 80.000 sulla Carta di credito CARTASI

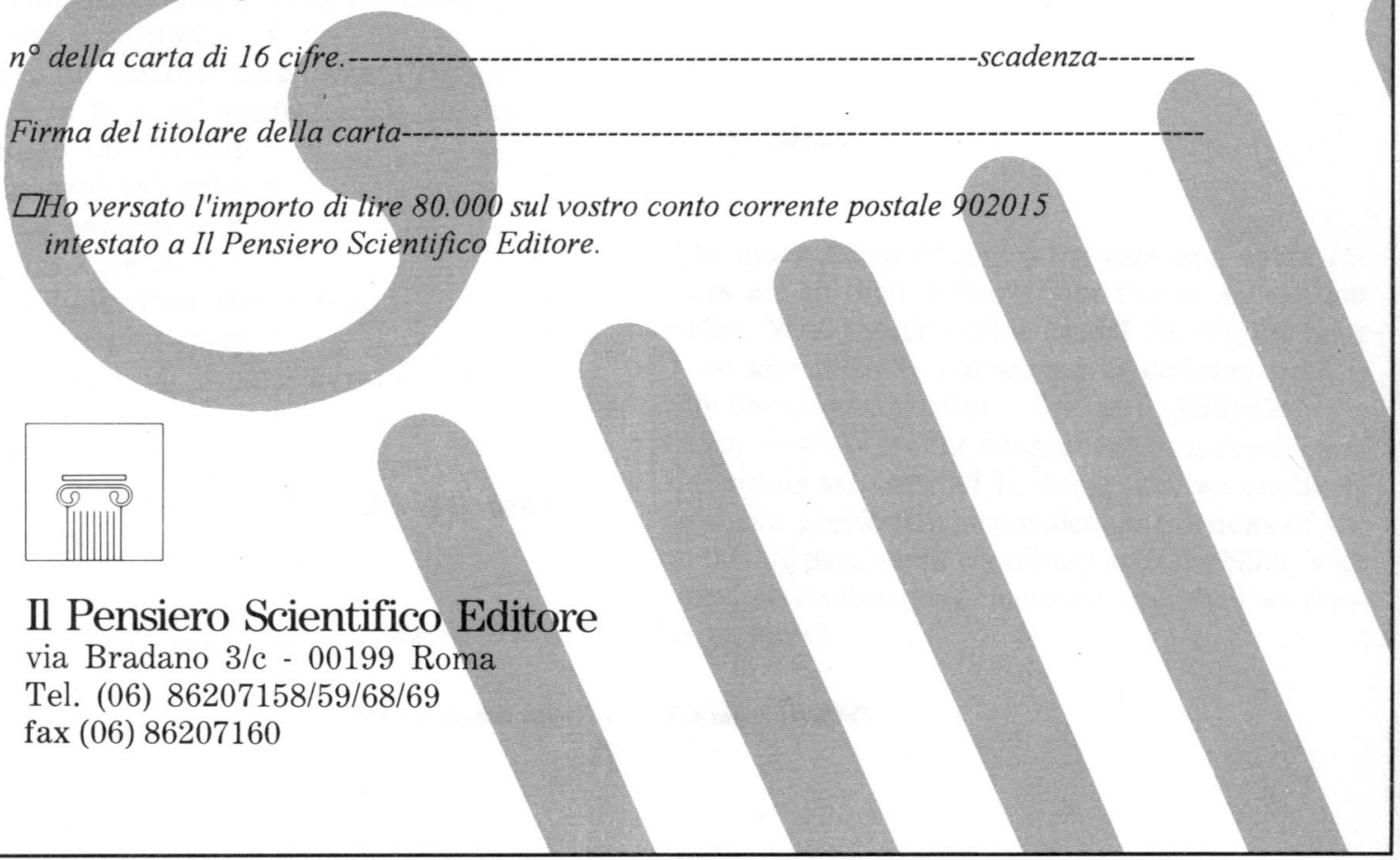

